\title{
Levantamento etnobotânico de plantas popularmente utilizadas como antiúlceras e antiinflamatórias pela comunidade de Pirizal, Nossa Senhora do Livramento-MT, Brasil
}

\author{
Neyres Zínia Taveira de Jesus, Joaquim Corsino da Silva Lima, Regilane Matos da Silva, \\ Mariano Martinez Espinosa, Domingos Tabajara de Oliveira Martins*
}

\author{
Departamento de Ciências Básicas em Saúde, Faculdade de Ciências Médicas, Universidade Federal de Mato \\ Grosso, Av. Fernando Correa da Costa, s/n, Campus Universitário 78060-900 Cuiabá-MT, Brasil
}

\begin{abstract}
RESUMO: O trabalho teve por objetivo proceder o levantamento etnobotânico das espécies vegetais utilizadas popularmente no Distrito de Pirizal - MT, no pantanal mato-grossense, como antiúlceras e antiinflamatórias. A entrevista aberta foi realizada através da aplicação de um roteiro base a 38 informantes adultos, na faixa etária de 25 a 75 anos. Indagou-se o nome popular das plantas, partes utilizadas, preparados e vias de administração, e realizou-se a revisão bibliográfica das plantas mais citadas no estudo, utilizando-se as bases de dados convencionais. Foram citadas 49 espécies pertencentes a 47 gêneros e 32 famílias, destacando-se a família Fabaceae. As plantas mais citadas simultaneamente como antiúlceras e antiinflamatórias foram Lafoensia pacari St. Hil. (9,2\%), Hyptis crenata Pohl (8,8\%), Hyptis suaveolens (L.) Poit (6,7\%), Stachytarpheta cayenensis (L.C.Rich) Vahl (5,8\%), Waltheria indica L. (5\%), Strychnos pseudoquina St. Hil. $(4,2 \%)$ e Vatairea macrocarpa (Benth.) Ducke (3,3\%). A parte da planta mais citada foi a folha $(57,1 \%)$, a via de administração mais utilizada no tratamento das úlceras gástricas foi a oral $(100 \%)$, com preferência para os chás $(75 \%)$, enquanto nas inflamações foram os banhos tópicos $(60 \%$.). A revisão bibliográfica apontou a necessidade de aprofundar os estudos químicofarmacológicos para Vatairea macrocarpa (Benth.) Ducke e Hyptis crenata Pohl.
\end{abstract}

Unitermos: Pantanal, plantas medicinais, etnobotânica, antiinflamatórias, antiúlceras.

\begin{abstract}
Ethnobotanical survey of plants popularly used as anti-ulcer and antiinflammatory in Pirizal, Nossa Senhora do Livramento, MT, Brazil". An ethnobotanical survey was conduced to study the vegetal species from Pantanal, in the district of Pirizal-MT, popularly used as anti-inflammatory and anti-ulcer. Ethnobotanical data were collected through open interviews and ethnopharmacology questionnaire with 38 local informers, in the age group of 25 to 75 years old. The local name, the part normally used, the mode of preparation and the administration route were asked to them. A bibliographic review of the plants most cited in the study was carried out using the conventional databases. A total of 49 species were cited belonging to 47 genera and 32 families, with emphasizing the Fabaceae family. The plants most cited were Lafoensia pacari St. Hil (9.2\%), Hyptis crenata Pohl (8.8\%), Hyptis suaveolens (L.) Poit (6.7\%), Stachytarpheta cayenensis (L.C.Rich) Vahl (5.8\%), Waltheria indica L. (5\%), Strychnos pseudoquina St.Hil (4.2\%) and Vatairea macrocarpa (Benth.) Ducke (3.3\%). The part of the plant most cited was the leaf $(57.1 \%)$, the most used administration route in the treatment of ulcers was oral $(100 \%)$, in the form of teas $(75 \%)$, while in the inflammations, topical baths were preferentially used $(60 \%)$. The literature review indicated the need for further chemicalpharmacological studies on Vatairea macrocarpa (Benth.) Ducke and Hyptis crenata Pohl.
\end{abstract}

Keywords: Pantanal, medicinal plants, ethnobotany, anti-inflammatory, anti-ulcer.

\section{INTRODUÇÃO}

A etnobotânica, segundo Caballero (1979), compreende o estudo e a interpretação do conhecimento, significação cultural, manejo e os usos tradicionais dos elementos da flora. Para Amorozo (1996), engloba a maneira como um grupo social classifica as plantas e as utiliza. $\mathrm{O}$ conhecimento tradicional sobre o uso das plantas é vasto e, em muitos casos, o único recurso terapêutico disponível às populações rurais de países em desenvolvimento (Pasa et al., 2005; Agra et al., 2007, 2008; Veiga-Junior et al., 2008), tais como o Brasil. Nestas localidades, em geral, não existem farmácias comerciais e o suprimento de medicamentos do Sistema Único de Saúde (SUS) é irregular e, portanto, o conhecimento e a utilização de plantas medicinais pela 
população destas áreas são de grande valor e, muitas vezes, a única opção no tratamento das enfermidades. No pantanal mato-grossense existem inúmeras destas pequenas localidades rurais.

O complexo do pantanal é uma depressão sazonalmente inundada e abrange no território brasileiro uma área de $150.355 \mathrm{Km}^{2}$ nos Estados de Mato Grosso e Mato Grosso do sul, no centro oeste brasileiro (Abdon et al., 2007). É um bioma caracterizado pela riqueza e abundância de espécies vegetais que são intensamente influenciadas pelo pulso das inundações, sendo considerado a maior área alagada do mundo. É um mosaico, com plantas oriundas do Chaco, Cerrado, Amazônia e Mata Atlântica (Pott \& Pott, 1994).

As primeiras informações sobre a flora pantaneira realizadas por naturalistas europeus datam do final do século XIX (Salis et al., 2006). Diversos autores têm se dedicado ao estudo das espécies vegetais pantaneiras e colaborado para o melhor entendimento da formação deste complexo ambiente. Os padrões e processos dos ecossistemas do pantanal são regulados pelo ciclo anual das inundações e secas, sendo que a distribuição das espécies e a sua diversidade variam desde as espécies não inundáveis, espécies sazonais e as que estão em áreas permanentemente inundadas (Rebellato \& Cunha, 2005), de forma a constituir um ambiente único, caracterizado pela presença de elementos vegetais de outros biomas.

Possui clima tropical quente e sub-úmido, com cinco meses de seca entre os meses de maio a setembro. De outubro a março estão os meses chuvosos, responsáveis em média por mais de $80 \%$ das precipitações anuais compreendidas entre 1000 e 1200 mm (Câmara \& Vital, 2004).

A presença no Pantanal de populações tradicionais, que utilizam plantas medicinais $\mathrm{e}$ habitualmente transmitem seus conhecimentos para seus descendentes, faz da região um importante campo para estudos etnobotânicos (Gonçalves \& Martins, 1998; Amorozo, 2002; Rodrigues \& Carlini, 2003; Macedo \& Ferreira, 2004; Guarin Neto, 2006).

Nos pantanais mato-grossenses existem muitas plantas medicinais que são utilizadas como recurso no tratamento de diversas doenças pela população de pequenas comunidades, inclusive plantas utilizadas para combater os problemas de estômago e inflamações (Rodrigues \& Carlini, 2003).

Dentre os problemas gástricos que podem acometer os indivíduos, as úlceras pépticas são consideradas importantes, em razão da alta prevalência mundial, estimada em aproximadamente 10\% (ZapataColindres et al., 2006). Constitui-se doença pluricausal, que segundo Glavin \& Szabo (1992) é decorrente do rompimento no equilíbrio entre os fatores agressivos e defensivos da mucosa gastrintestinal, sendo o Helicobacter pylori considerado um relevante agente etiológico da úlcera péptica em humanos (Stamatis et al., 2003).

Já o processo inflamatório, faz parte da estratégia de sobrevivência dos organismos contra as injúrias decorrentes das infecções e traumas. Em geral, a resposta inflamatória tem como resultado o restabelecimento da integridade orgânica contra as agressões, entretanto, pode ocorrer uma resposta excessiva provocando aumento de morbidade e mortalidade em doenças como artrite reumatóide, diabetes, esclerose múltipla e aterosclerose com isquemia cerebral e miocárdica (Tracey, 2002).

Segundo Carvalho (2004), as investigações etnofarmacológicas de plantas com potencialidade antioxidante costuma ser realizada com plantas que exibem propriedades antiúlcera e antiinflamatória. A inflamação e úlcera têm em comum o estresse oxidativo gerado, entre outros fatores, pela atividade aumentada de células fagocitárias nos locais das lesões. A atividade antioxidante gástrica de compostos vegetais têm atraído interesse, em virtude da forte evidência que o processo oxidativo está envolvido nos mecanismos de diversas patologias que acometem o estômago, incluindo a ulcerogênese (Repetto \& Llessuy, 2002).

Os levantamentos etnobotânicos podem subsidiar estudos etnofarmacológicos na busca por fitoterápicos para o tratamento de úlceras pépticas, inflamações e outras enfermidades (Albuquerque \& Hanazaki, 2006). Segundo a Política Nacional de Plantas Medicinais e Fitoterápicos, as plantas medicinais são consideradas estratégicas para o fortalecimento da agricultura familiar, geração de emprego e renda, uso sustentável da biodiversidade brasileira, avanço tecnológico e melhoria da atenção à saúde da população brasileira (Brasil, 2006).

Com base no exposto, realizou-se esse estudo na comunidade de Pirizal, em Nossa Senhora do Livramento - MT, tendo como objetivo principal levantar as principais espécies vegetais utilizadas como antiúlceras e antiinflamatórias, selecionando-se as mais indicadas para revisão de literatura.

\section{MATERIAL E MÉTODOS}

O estudo foi realizado na comunidade de Pirizal, no município de Nossa Senhora do Livramento - MT, Brasil, nos meses de outubro de 2005 a junho de 2007. A região é conhecida localmente como "Pantanal de Poconé", estando situada à margem direita do rio Cuiabá e a margem esquerda do rio Bento Gomes. O ponto central da localidade está entre as coordenadas geográficas $16^{\circ} 14^{\prime} 06^{\prime \prime} \mathrm{S}$ de latitude e $56^{\circ} 22^{\prime} 70^{\prime \prime} \mathrm{W}$ de longitude (Figura 1).

Apresenta baixa densidade populacional, constituído por 513 moradores, reunidos em 56 famílias, sendo que a organização social é centralizada nas famílias e no grau de parentesco (Pinho, 2000). É local de difícil acesso no período de inundação (outubro 
a abril), não possui estrada pavimentada, o que dificulta $\mathrm{o}$ acesso.

Uma vez que um dos objetivos principais da pesquisa foi determinar a proporção de indivíduos adultos que fazem uso de plantas medicinais em PirizalMT, considerou-se, segundo Da Silva (2001), na determinação do tamanho da amostra $(n)$, um coeficiente de confiança de $95 \%(z=1,96)$, um erro amostral $(d=$ $0,15)$, uma proporção a ser estimada $(p=0,5)$ e uma população $(N)$ de 308 indivíduos entre 25 e 75 anos, segundo o Sistema de Informações de Atenção Básica em Saúde (SIAB, 2005), utilizando-se a expressão abaixo e chegando-se a uma amostra representativa $(n)$ de 38 indivíduos.

$$
n=\frac{N p(1-p)}{(N-1)(d / z)^{2}+p(1-p)},
$$

O instrumento de coleta de dados é formado por três partes: a primeira, refere-se aos dados sóciodemográficos (idade, sexo, procedência); a segunda, por dados botânicos (nome popular da planta) e, a terceira, por dados farmacêuticos (indicação, parte utilizada, forma de preparo e via de administração).

As perguntas sobre o uso terapêutico das plantas foram restritas ao tratamento das afecções gástricas e inflamatórias. Para a obtenção das informações sobre a atividade antiúlcera foram utilizados os seguintes termos: úlcera, gastrite, dor no estômago, azia, queimação, sangramentos gástricos e empachação. Para a obtenção das informações sobre a atividade antiinflamatória, os termos usados foram: inflamação, dores, reumatismo, machucadura e inchaço. Pelas particularidades da pesquisa, o roteiro base das perguntas foi adaptado de Camargo (1985), Martin (1995) e Alexiades \& Sheldon (1996).

Optou-se por entrevistar os moradores adultos, homens e mulheres, que costumam fazer uso de plantas medicinais no seu cotidiano. As entrevistas foram acompanhadas por uma moradora local que facilitou o acesso da pesquisadora às residências. As entrevistas foram realizadas no período diurno, considerando que o preparo das plantas medicinais é geralmente tarefa das mulheres e que nesta localidade, elas estão em casa durante o dia, realizando as lidas domésticas. Os homens também foram questionados quanto ao uso de plantas medicinais e quando a resposta era afirmativa procedia- se a entrevista. Também optou-se em entrevistar pessoas com mais idade, considerando o conhecimento acumulado e a tradição de transmissão oral pelos indivíduos mais idosos nas comunidades rurais (Guarim Neto, 1987).

Após as entrevistas, procedeu-se com a coleta do material botânico nos locais indicados pelos informantes, com a colaboração dos mesmos na realização da coleta das plantas citadas, seguida pela montagem das exsicatas, conforme orientações citadas por Macedo et al. (1998).

Todas as plantas citadas pelos informantes foram incorporadas ao acervo do Herbário Central da Universidade Federal de Mato Grosso. Amostras com flores das plantas mais citadas foram enviadas ao Instituto Plantarum para Estudos da Flora, em Nova Odessa-SP, para ratificação taxonômica.

As sete plantas mais indicadas no estudo, utilizadas simultaneamente como antiúlceras e antiinflamatórias, foram submetidas a uma revisão bibliográfica, utilizando-se as bases de dados da Biblioteca Regional de Medicina da Unifesp (BIREME) e Periódicos disponíveis no Portal da Coordenação de Aperfeiçoamento do Pessoal de Nível Superior (CAPES) dentre outros, para aferição das informações complementares. Os estudos para Hyptis crenata Pohl, Hyptis suaveolens (L.) Poit, Waltheria indica L., Strychnos pseudoquina St. Hil. e Vatairea macrocarpa (Benth) Ducke foram particularmente aprofundados, por tratarem-se de espécies nativas que ainda não haviam sido investigadas no Laboratório de Farmacologia de Produtos Naturais da UFMT.

\section{RESULTADOS}

Foram entrevistados 38 informantes, abrangendo $12,3 \%$ da população adulta ( 25 a 75 anos) do Distrito de Pirizal (308 pessoas). Dos entrevistados, 83,3\% foram do sexo feminino e $16,7 \%$ do sexo masculino. Dentre os entrevistados, 37 são oriundos de Mato Grosso, sendo apenas um procedente de Mato Grosso do Sul. Dentre os participantes da pesquisa, 92\% pertenciam à área rural de Nossa Senhora do Livramento-MT.

Foram entrevistados os indivíduos adultos, especialmente os moradores mais antigos da comunidade.

Os dados botânicos referentes às plantas citadas no estudo encontram-se na Tabela 1 , assim como os nomes populares, parte utilizada, local de coleta e forma de preparo dos "remédios caseiros".

Foram citadas 49 espécies de plantas pertencentes a 47 gêneros e 32 famílias, sendo que para uma das plantas (Caparia sp), a identificação da espécie ainda não foi concluída. Dentre as famílias referidas (31), a que mais se destacou foi a Fabaceae $(14,1 \%$ das espécies citadas).

As plantas mais citadas como antiúlceras e antiinflamatórias foram Lafoensia pacari A. St. Hil. (9,2\%), Hyptis crenata Pohl (8,8\%), Hyptis suaveolens (L.) Poit (6,7\%), Stachytarpheta cayenensis (L.C.Rich) Vahl $(5,4 \%)$, Waltheria indica L. (5\%), Strychnos pseudoquina St. Hil $(4,2 \%)$ e Vatairea macrocarpa (Benth.) Ducke (3,3\%).

A parte da planta mais citada na preparação dos "remédios caseiros" foi a folha $(57,1 \%)$, seguida por entrecasca $(20,4 \%)$, planta inteira $(8,2 \%)$, raiz 
$(6,1 \%)$, fruto $(4,1 \%)$, cerne $(2 \%)$ e xilopódio $(2 \%)$. No tratamento da úlcera gástrica, a via de administração mais empregada foi a oral $(100 \%)$, na forma de infusão (75\%) ou macerada em água fria (25\%). No tratamento das inflamações foram preferencialmente utilizados banhos tópicos $(60 \%)$, especialmente nas inflamações do trato geniturinário, além da via oral $(40 \%)$ para ações sistêmicas.

\section{DISCUSSÃO}

Foram entrevistadas 38 pessoas. Em relação à variável sexo, a maioria dos entrevistados foi do sexo feminino, dados semelhantes aos encontrados por Gonçalves \& Martins (1998), em estudo etnobotânico realizado na mesma microrregião geográfica. Estes resultados podem dever-se ao fato de que no momento da entrevista (período diurno), os homens encontravamse no trabalho e as mulheres envolvidas com as tarefas domésticas.

Dentre os entrevistados, 37 são oriundos de Mato Grosso, sendo apenas um procedente de Mato Grosso do Sul. Dentre os participantes da pesquisa, $92 \%$ pertenciam à área rural de Nossa Senhora do Livramento-MT. Estes dados estão de acordo com o censo demográfico, que aponta a maioria da população do município pertencente à área rural (Seplan, 2005).

Foram entrevistados os indivíduos adultos, especialmente os moradores mais antigos da comunidade. A constatação de que as indicações sobre o uso de plantas medicinais foram fornecidas em sua grande maioria por pessoas de mais idade da comunidade, como mães e avós, pode conferir maior confiabilidade às informações. Guarim Neto (1987) destaca que as pessoas mais idosas são detentoras de preciosas informações sobre o uso de plantas e que estas podem subsidiar o conhecimento do potencial terapêutico da flora mato-grossense e nacional.

Dentre as famílias, a que mais se destacou foi a Fabaceae, sendo esta constituída por aproximadamente 440 gêneros e cerca de 12.000 espécies, estando bem representada nas regiões tropicais (Polhill, 1981) e, segundo Pott \& Pott (1994), é a família mais numerosa de plantas do Pantanal.

A folha foi a parte da planta mais utilizada na preparação dos "remédios caseiros", da mesma forma como encontrado em levantamento realizado por Medeiros et al. (2004). A folha é a parte vegetal de mais fácil coleta e cuja obtenção causa menos prejuízos às plantas (Gonçalves \& Martins, 1998).

O local de coleta predominante foi o campo (51\%), visto que o distrito de Pirizal está localizado em região cuja vegetação nativa está preservada em seu entorno. Os informantes, durante a coleta das plantas, relataram existir uma satisfação em adentrar na mata e que o contacto com a natureza é uma tarefa cotidiana na região e, de certa forma, reverenciada por seus moradores.

Dentre as plantas mais citadas, existem estudos demonstrando a atividade antiúlcera de Lafoensia pacari. Tamashiro (1999), utilizando o extrato metanólico desta planta, procedeu a validação pré-clínica da sua atividade antiúlcera. Menezes et al. (2006), demonstraram sua atividade antiúlcera em ensaios clínicos. A atividade

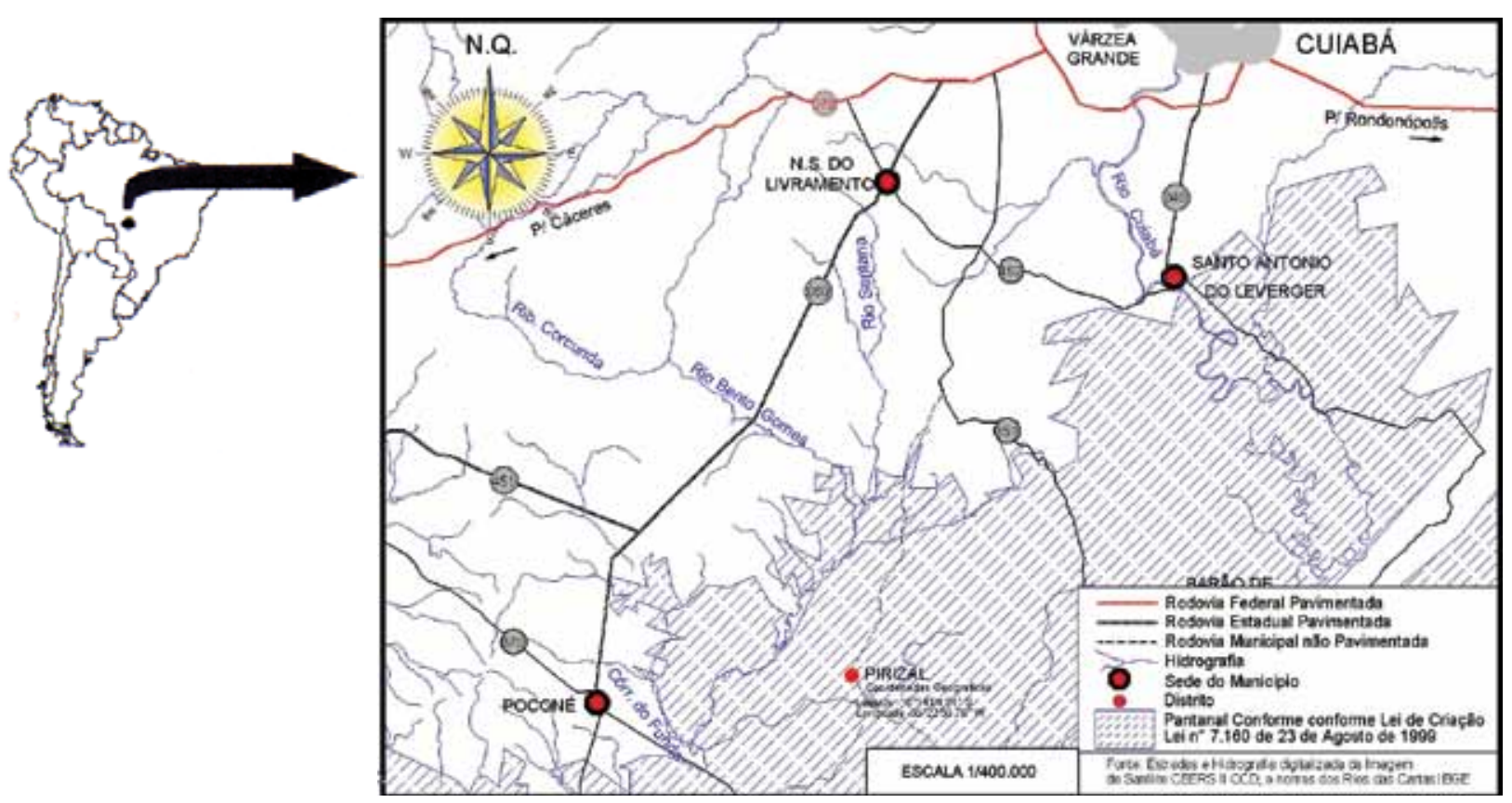

Figura 1 Mapa de localização da área de estudo, distrito de Pirizal, em Nossa Senhora do Livramento, Pantanal matogrossense, MT. 
antiinflamatória de Lafoensia pacari foi demonstrada por Rogerio et al. (2006) e Rogerio et al. (2008a). Seu efeito anti-eosinofílico na toxocaríase por Rogerio et al. (2008b). A atividade de varredura de radicais livres do extrato bruto, frações e ácido elágico obtidos da entrecasca de Lafoensia pacari foi demonstrada por Solon et al. (2000). Um estudo utilizando um modelo experimental clássico de asma induzida por ovalbumina mostrou que tanto o extrato etanólico das cascas dos caules de Lafoensia pacari quanto o ácido elágico foram capazes de diminuir o número de neutrófilos e eosinófilos no lavado broncoalveolar e no parênquima pulmonar (Corrêa et al., 2008). Para Hyptis suaveolens (L.) Poit, a literatura refere-se a estudos químicos de caracterização de polissacarídeo das sementes (L-fuco4-O-metil-D-glucurono-D-xilano) e isolamento de óleos essenciais (sabineno, beta-felandreno, limoneno, biciclogemacreno e 1,8 cineol) e diterpenóides das folhas (Aspinall et al., 1991; Azevedo et al., 2001; Chukwujekewu et al., 2005). Foram descritos ensaios farmacológicos para atividade antioxidante (Shirwaikar et al., 2003) e antiinflamatória (Grassi et al., 2006), sem relatos para atividade antiúlcera.

Vários estudos foram conduzidos atestando atividades farmacológicas para Stachytarpheta cayennensis (L. C. Rich) Vahl (Hammer \& Johns, 1993; Almeida et al., 1995; Froelich et al., 2008; Moreira et al., 2007), inclusive sua comprovação como antiúlcera e antiinflamatória, em animais de laboratório, conforme demonstrado por Penido et al. (2006).

Rao et al. (2005) isolaram flavonóides das partes aéreas da Waltheria indica e ensaios farmacológicos préclínicos demonstraram sua atividade antiinflamatória.

Em relação à Vatairea macrocarpa (Benth.) Ducke foram isolados o ácido crisofânico e 7-hidroxiflavona do cerne (Matos et al., 1988) e a purificação de lectina das sementes (Cavada et al., 1998; Calvete et al., 1998). Estudos farmacológicos utilizando sementes dessa planta mostraram atividade pró-inflamatória em modelos animais (Teixeira et al., 2006; Alencar et al., 2004, 2007), ao contrário da indicação popular de uso do cerne da planta como antiinflamatória, necessitando-se, portanto, de estudos farmacológicos para as atividades indicadas, utilizando o cerne na preparação dos extratos.

Nicoletti et al. (1984) isolaram uma biflavona das folhas de Strychnos pseudoquina St. Hil. . Silva et al. (2005) demonstraram atividade gastroprotetora para o extrato metanólico das folhas desta planta. Apesar da população do Distrito de Pirizal ter citado a entrecasca de Strychnos pseudoquina St. Hil., é importante para efeitos de preservação desta espécie, proceder os estudos químico-farmacológicos com as folhas.

No caso de Hyptis crenata Pohl não existem relatos de estudos químicos e farmacológicos da planta na literatura científica.

\section{CONCLUSÃO}

Pode-se concluir que dentre as principais plantas utilizadas como antiúlceras e antiinflamatórias pela população do Distrito de Pirizal, existe respaldo científico para o uso de Lafoensia pacari e Stachytarpheta cayenensis, entretanto, para esta última, os estudos farmacológicos se restringem à experimentação em animais.

Para Hyptis suaveolens, os ensaios farmacológicos demonstraram sua atividade antiinflamatória, sem relatos para a atividade antiúlcera.

Dentre as plantas citadas neste levantamento as que foram menos estudadas, até o momento, sob o aspecto químico-farmacológico foram Vatairea macrocarpa e Hyptis crenata.

\section{AGRADECIMENTOS}

Os autores são gratos a todos que contribuíram para a realização deste trabalho, em especial à FAPEMAT pelo apoio financeiro ao projeto, ao CNPq e à CAPES pelas concessões, respectivamente, de bolsas de Mestrado e Pró-Doc, ao Instituto Plantarum da Flora pela ratificação taxonômica e a senhora Pedrosa Moraes de Arruda (Dona Bugra) pela facilitação do acesso da pesquisadora aos lares na comunidade de Pirizal.

\section{REFERÊNCIAS}

Abdon MM, Silva JSV, Souza IM, Romon VT, Rampazzo J, Ferrari DL 2007. Desmatamento no bioma pantanal até o ano de 2002: Relações com a fitofisionomia e limites municipais. Revista Brasileira de Cartografia 59: 17-24.

Albuquerque UP, Hanazaki N 2006. As pesquisas etnodirigidas na descoberta de novos fármacos de interesse médico e farmacêutico: fragilidades e pespectivas. Rev Bras Farmacogn 16 (Supl.): 678-689.

Alencar NM, Assreuy AM, Criddle DN, Souza EP, Soares PM, Havt A, Aragão KS, Bezerra DP, Ribeiro RA, Cavada BS 2004. Vatairea macrocarpa lectin induces paw edema with leukocyte infiltration. Protein Peptide Lett 11: 195-200.

Alencar NM, Assreuy AM, Havt A, Benevides RG, De Moura TR, De Sousa RB, Ribeiro RA, Cunha FQ, Cavada BS 2007. Vatairea macrocarpa (Leguminosae) lectin activates cultured macrophages to release chemotactic mediators. N-S Arch Pharmacol 374: 275-282.

Alexiades MN, Sheldon JW 1996. Ethnobotanical Research: A. Field manual. Bronx, New York, The New York Botanical Garden.

Almeida CE, Karnikowski MG, Foleto R, Baldisserotto B 1995. Analysis of antidiarrholic of plants used in popular medicine. Rev Saude Publ 29: 428-33.

Agra MF, França PF, Barbosa-Filho JM 2007. Synopsis of the plants known as medicinal and poisonous in Northeast of Brazil. Rev Bras Farmacogn 17: 114140.

Agra MF, Silva KN, Basílio IJLD, França PF, Barbosa-Filho JM 2008. Survey of medicinal plants used in the 


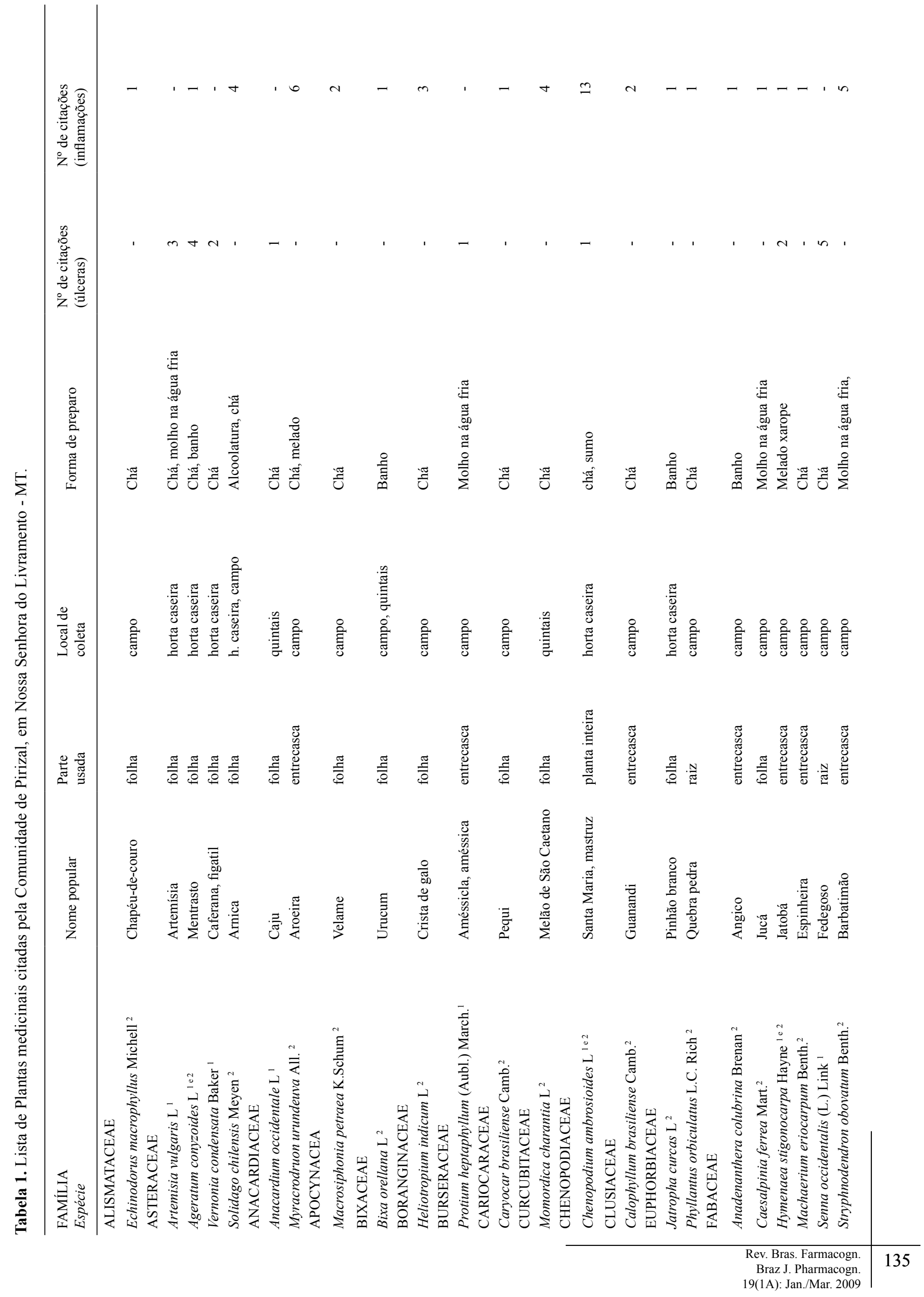




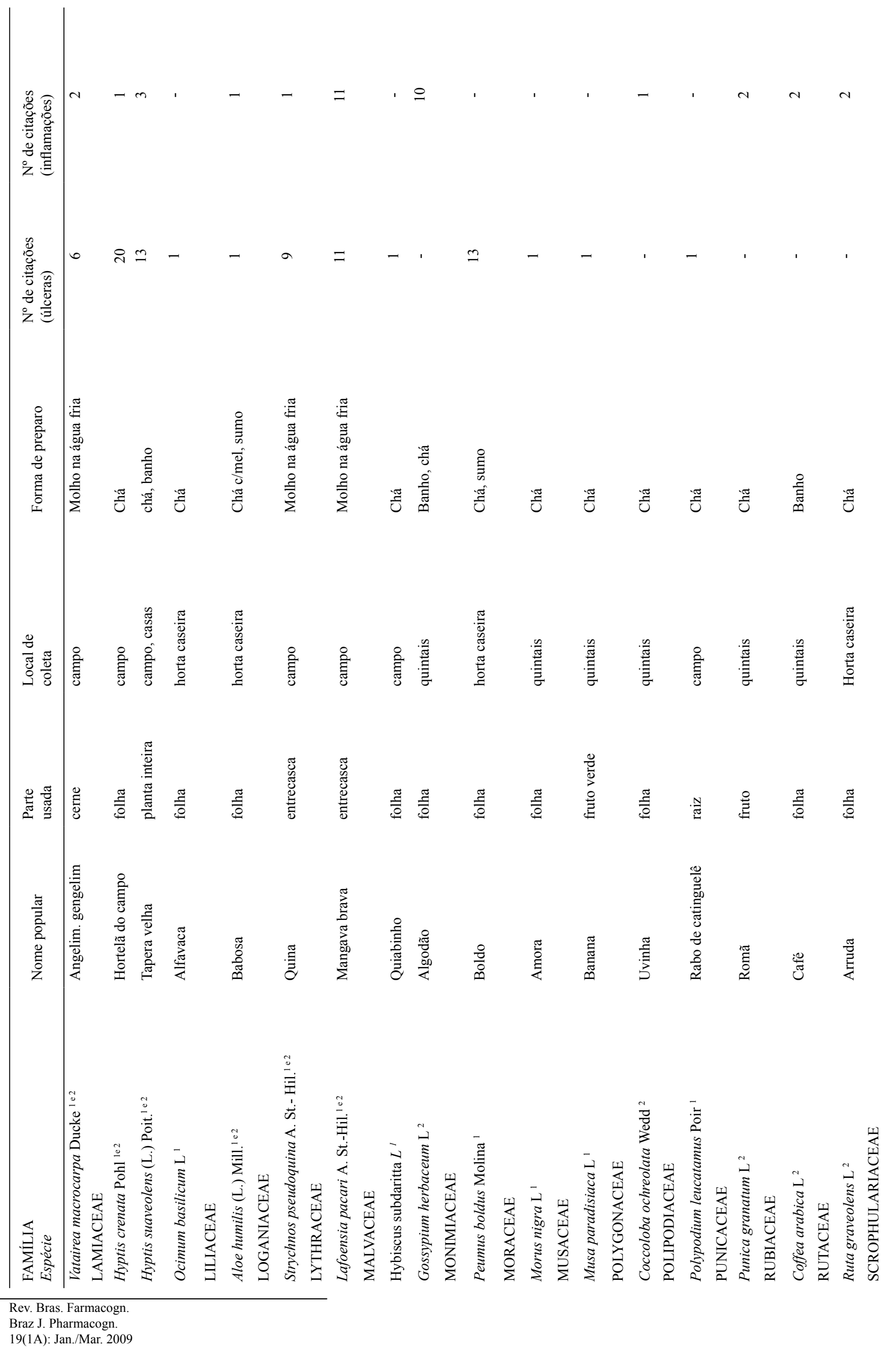




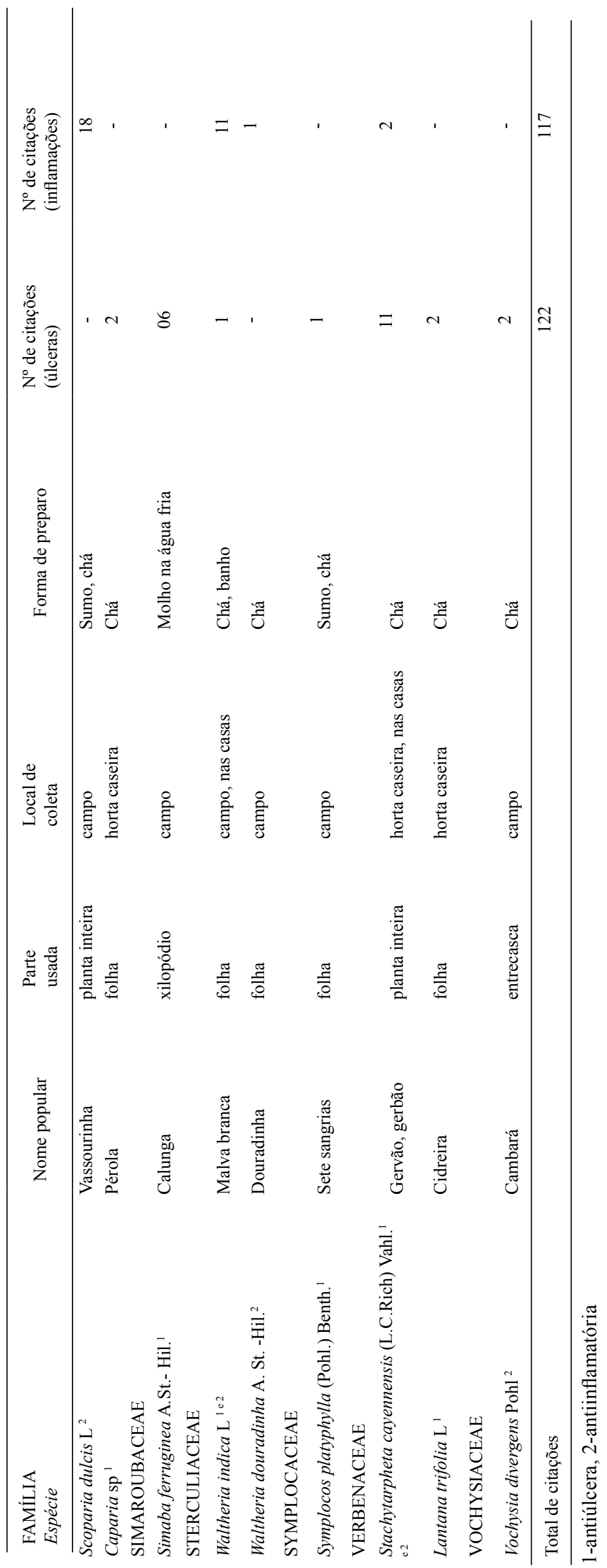


region Northeast of Brazil. Rev Bras Farmacogn 18: 472-508.

Amorozo MCM 1996. A abordagem etnobotânica na pesquisa de plantas medicinais. Pp.47-68. In: di Stasi, L.C. (Org). Editora da Universidade Estadual Paulista. Plantas medicinais Arte e ciência - um guia de estudo interdisciplinar. São Paulo.

Amorozo MCM 2002. Uso e diversidade de plantas medicinais em Santo Antônio do Leverger, MT, Brasil. Act Bot Bras 16: 189-203.

Aspinall GO, Capek P, Carpenter RC, Gowda DC, Szafranek J 1991. A novel 1-fuco-4-O-metyl-D-glucurono-Dxylan from Hyptis suaveolens. Carbohyd Res 214: 107-113.

Azevedo NR, Campos IF, Ferreira HD, Portes TA, Santos SC, Seraphin JC, Paula JR, Ferri PH 2001. Chemical variability in the essential oil of Hyptis suaveolens. Phytochemistry 57: 733-736.

Brasil 2006. Ministério da Saúde. Secretaria de Ciência, Tecnologia e Insumos Estratégicos. Departamento de Assistência Farmacêutica. Política Nacional de plantas medicinais e fitoterápicos. Brasília.

Caballero J 1979. La etnobotânica. Pp. 27-30. In: A. Barrera (ed). INREB. La etnobotânica: três puntos de vista y una perspectiva. Xalapa.

Calvete JJ, Santos CF, Mann K, Grangeiro TB, Nimtz M, Urbanke C, Cavada BS 1998. Amino acid sequence, glycan structure, and proteolytic processing of the lectin of Vatairea macrocarpa seeds. FEBS Lett 425 : 286-292.

Câmara PEA, Vital DM 2004. Briófitas do Município de Poconé, Pantanal de Mato Grosso, MT, Brasil. Acta Bot Bras 18: 881-886.

Camargo, MTLA 1985. A Medicina popular - aspectos metodológicos para pesquisa: garrafadas, objeto de pesquisa, componentes vegetais de origem vegetal, animal e mineral. São Paulo, ALMED.

Carvalho JCT 2004. Fitoterápicos anti-inflamatórios: aspectos químicos, farmacológicos e aplicações terapêuticas. Tecmedd. Ribeirão Preto-SP.

Cavada BS, Santos CF, Grangeiro TB, Nunes EP, Sales PV, Ramos RL, De Sousa FA, Crisostomo CV, Calvete JJ 1998. Purification and characterization of a lectin from seeds of Vatairea macrocarpa Duke. Phytochemistry 49: 675-80.

Chukwujekwu JC, Smith P, Coombes PH, Mulholland DA, Vanstaden J 2005. Antiplasmodial diterpenoid from the leaves of Hyptis suaveolens. J Ethnopharmacol 102: 295-297.

Corrêa MFP, Melo GO, Costa SS 2008. Substâncias de origem vegetal potencialmente úteis na terapia da Asma. Rev Bras Farmacogn 18 (Supl.): 785-797.

Da Silva NN 2001. Amostragem probabilística: Um curso introdutório. Edusp Editora da Universidade de São Paulo-Edusp. p. 120.

Froelich S, Gupta MP, Siems K, Jenett-Siems K 2008. Phenylethanoid glycosides from Stachytarpheta cayennensis (Rich.) Vahl, Verbenaceae, a traditional antimalarial medicinal plant. Rev Bras Farmacogn 18: 517-520.

Glavin GB, Szabo S 1992. Experimental gastric mucosal injury: laboratory models reveal mechanisms of pathogenesis and new terapeutic strategies. FASEB
J 6: 825-831.

Gonçalves MIA, Martins DTO 1998. Plantas medicinais usadas pela população do município de Santo Antônio de Leverger, Mato Grosso, Brasil. Rev Bras Farm 79: 56-61.

Guarim Neto G 1987. Plantas utilizadas na medicina popular do Estado de Mato-Grosso. Brasília. CNPq. Assessoria editorial.

Guarim Neto G 2006. O saber tradicional Pantaneiro: as plantas medicinais e a educação ambiental. Revista Eletrônica do Mestrado em Educação Ambiental 17: 71-89.

Grassi P, Urias-Reyes TS, Sosa S, Tubaro A, Hofer O, ZitterlEglseer K 2006. Anti-inflammatory activity of two diterpenes of Hyptis suaveolens from El Salvador. $Z$ Naturforsch 61c: 165-170.

Hammer ML, Johns EA 1993. Tapping an Amazônian plethora: four medicinal plants of Marajó Island, Pará (Brazil). J Ethnopharmacol 40: 53-75.

Macedo M, Pinto AS, Somavilla N 1998. Guia do Herbário Central da UFMT. Cuiabá, UFMT.

Macedo M, Ferreira AR 2004. Plantas hipoglicemiantes utilizadas por comunidades tradicionais na Bacia do Alto Paraguai e Vale do Guaporé, Mato GrossoBrasil. Rev Bras Farmacogn 14 (Supl. 1): 45-47.

Martin GJ 1995. Ethnobotany: A methods manual. Ed. Chapman \& Hall. London.

Matos FJA, Aguiar LMBA, Silva MGV 1988. Constituintes químicos e atividade antimicrobiana de Vatairea macrocarpa Duke. Acta Amazonica 18: 351-352.

Medeiros MFT, Fonseca VS, Andreata RHP 2004. Plantas medicinais e seus usos pelos sitiantes da reserva de Rio das Pedras, Mangaratiba, RJ, Brasil. Acta Bot Bras 18: 391-399.

Menezes MV, Atallah AN, Lapa AJ, Catapani WR 2006. Assessing the terapeutic use of Lafoensia pacari St. Hil. Extract (mangava brava) in the eradication of Helicobacter pylori: Double-blind randomized clinical trial. Helicobacter 11: 188-195.

Moreira RCR, Costa GC, Lopes TC, Bezerra JL, Guerra RNM, Rebêlo JMM, Ribeiro MNS, Nascimento FRF, Costa JML 2007. Efeito leishmanicida in vitro de Stachytarpheta cayennensis (Rich.) Vahl (Verbenaceae). Rev Bras Farmacogn 17: 59-63.

Nicoletti M, Goulart MO, De Lima RA, Goulart AE, Delle Monache F, Marini Bettolo GB 1984. Flavonoids and alkaloids from Strychnos pseudoquina. J Nat Prod 47: 953-957.

Pasa MC, Soares JJ, Guarim Neto G 2005. Estudo etnobotânico da comunidade de Conceição-Açu (alto da bacia do rio Aricá Açu, MT, Brasil) Acta Bot Bras 19: 195207.

Penido C, Costa KA, Futuro DO, Paiva SR, Kaplan MAC, Figueiredo MR, Henriques MGMO 2006. Antiinflammatory and antiulcerogenic properties of Stachytarpheta cayenensis (L.C.Rich) Vahl. J Ethnopharmacol 104: 225-233.

Pinho CF 2000. Interações ambientais, cotidianos e educação da comunidade do Pirizal-Pantanal de Mato Grosso. Cuiabá. Dissertação (Mestrado)-Universidade Federal de Mato Grosso.

Polhill RM 1981. Papilionoideae. In Advances in Legume Systematics I (R.M. Polhill \& P.H. Raven, eds.) 
Royal Botanic Gardens, Kew, p.191-208.

Pott VJ, Pott A 1994. Plantas do Pantanal. EMBRAPA-CPAP, Brasília.

Rao YK, Fang SH, Tzene YM 2005. Inhibitory effects of the flavonoids isoleted from Waltheria indica on the production of NO, TNF $\alpha$ and IL-2 in activated macrofages. Biol Pharm Bull 28: 912-915.

Rebellato L, Cunha, CN 2005. Efeito do fluxo sazonal mínimo da inundação sobre a composição e estrutura de um campo inundável no pantanal de Poconé, MT, Brasil. Acta Bot Bras 19: 789-799.

Repetto MG, Llessuy SF 2002. Antioxidant properties of natural compounds used in popular medicine for gastric ulcer. Braz J Med Biol Res 35: 523-534.

Rodrigues E, Carlini ELA 2003. Levantamento etnofarmacológico realizado entre um grupo de quilombolas do Brasil. Arquivos Brasileiros de Fitomedicina Científica 1: 80-87.

Rogerio AP, Fontanari C, Ambrósio SR, De Souza GE, França SC, Da Costa FB, Albuquerque DA, Faccioli LH 2006. Anti-inflammatory, analgesic, and antioedematous effects of Lafoensia pacari extract and ellagic acid. J Pharm Pharmacol 58: 1265-1273.

Rogerio AP, Fontanari C, Borducchi E, Keller AC, Russo M, Soares EG, Albuquerque DA, Faccioli LH 2008a. Anti-inflamatory effects of Lafoensia pacari and ellagic acid in a murine model of asthma. Eur $J$ Pharmacol 580: 262-270.

Rogerio AP, Sá-Nunes A, Albuquerque DA, Soares EG, Faccioli LH 2008b. Anti-eosinofhilic effect of Lafoensia pacari in toxocariasis. Phytomedicine 15: 348-357.

Salis SM, Assis MA, Crispim SMA, Casa Grande JC 2006. Distribuição e abundância de espécies arbóreas em cerradões no Pantanal, Estado de Mato Grosso do Sul, Brasil. Rev Bras Bot 29: 339-352.

Seplan 2005. Secretaria de Estado de Planejamento de Mato Grosso. Anuário Estatístico de Mato-Grosso-2004. Vol.26, Cuiabá. Seplan-MT.

Shirwaikar A, Shenoy R, Udupa AL, Udupa SL, Shetty S 2003. Wound healing property of ethanolic extract of leaves of Hyptis suaveolens with supportive role of antioxidant enzymes. Indian J Exp Biol 41: 238-241.

Silva MA, Rafacho BP, Hiruma-Lima CA, Rocha LRM, Santos LC, Sinnomiya M, Souza-Brito ARM, Vilegas W 2005. Evaluation of Strychnos pseudoquina St. Hil. leaves extract on gastrointestinal activity in mice. Chem Pharm Bull 53: 881-885.

SIAB 2005. Sistema de Informações da Atenção Básica em Saúde (SIAB).

Solon S, Lopes L, Souza Junior PT, Schmeda-Hirschmann G 2000. Free radical scavenging activity of Lafoensia pacari. J Ethnopharmacol 72: 173-178.

Stamatis G, Kyriazopoulos P, Golegou S, Basayiannis A, Skaltsas S, Skaltsa H 2003. In vitro anti-Helicobacter pylori activity of greek herbal medicines. $J$ Ethnopharmacol 88: 175-179.

Tamashiro Filho P 1999. Validação pré clínica da atividade antiúlcera do extrato bruto metanólico de Lafoensia pacari St. Hil. (mangava brava). Dissertação de mestrado, UFMT, MT, Brasil.

Teixeira EH, Napimoga MH, Carneiro VA, de Oliveira TM, Cunha RM, Havt A, Martins JL, Pinto VP,
Gonçalves RB, Cavada BS 2006. In vitro inhibition of Streptococci binding to enamel acquired pellicle by plant lectins. J Appl Microbiol 101: 111-116.

Tracey KJ 2002. The inflammatory reflex. Nature 420: 19-26.

Veiga-Junior VF 2008. Estudo do consumo de plantas medicinais na Região Centro-Norte do Estado do Rio de Janeiro: aceitação pelos profissionais de saúde e modo de uso pela população. Rev Bras Farmacogn 18: 308-313.

Zapata-Colindres JC, Zepeda-Gomez S, Montano-Loza A, Vazquez-Ballesteros E, Jesus-Villalobos J, Valdovinos-Andraca F 2006. The association of Helicobacter pylori infection and nonsteroidal antiinflammatory drugs in peptic ulcer disease. Can $J$ Gastroenterol 20: 277-280. 